\title{
Safety and clinical outcome in combination therapy for high-risk elderly hypertensive patients
}

\author{
Seiji Umemoto \\ Hypertension Research (2015) 38, 104-105; doi:10.1038/hr.2014.166; published online 27 November 2014
}

$\mathrm{T}_{\mathrm{r}}$ achieve the optimal target blood pressure level $(<140 / 90 \mathrm{~mm} \mathrm{Hg})$ for the prevention of cardiovascular events, various combinations of antihypertensive drugs are often required. ${ }^{1}$ Meta-analysis demonstrated that the blood pressure reduction effects of different categories of drugs were additive and adverse symptoms attributable to thiazide diuretics, $\beta$-blockers and calcium channel blockers (CCBs) were strongly dose related, whereas angiotensin receptor blockers (ARBs) caused no increase in symptoms. ${ }^{2}$ The extra blood pressure reduction from combining drugs from two different classes is approximately five times greater than doubling the dose of one drug, ${ }^{3}$ whereas the prevalence of symptoms with two drugs in combination was less than additive and adverse metabolic effects were negligible at half the standard dose, indicating that lowdose combination treatment increases the efficacy of treatment and reduces adverse drug reactions. ${ }^{2}$ According to the current Japanese Society of Hypertension Guideline for the Management of Hypertension (JSH 2014), ${ }^{1}$ if antihypertensive effects are insufficient, among the combinations of two drugs, those of angiotensin-converting enzyme (ACE) inhibitor or ARB+CCB, ACE inhibitor or $\mathrm{ARB}+$ thiazide diuretic and $\mathrm{CCB}+$ thiazide diuretic are recommended. It is reported that, according to the trends in the prescription of antihypertensive drugs in Japan, the two most prescribed classes of antihypertensive drugs were ARBs and CCBs, and the prescription rate for thiazide diuretics has increased, but the rate of its increase was unchanged during the study period. ${ }^{4}$

S Umemoto is at Center for Clinical Research, Yamaguchi University Hospital, Ube, Yamaguchi 755-8505, Japan

E-mail: umemoto@yamaguchi-u.ac.jp
In this issue, Saruta et al. ${ }^{5}$ reported findings regarding safety and tolerability as a subanalysis of the Combinations of OLMesartan (COLM) study. Few clinical studies have prospectively compared regimens for combination therapy in elderly hypertensive patients. The Avoiding Cardiovascular Events through Combination Therapy in Patients Living with Systolic Hypertension (ACCOMPLISH) trial involves fixed-dose drug combinations in a double-blind clinical trial ${ }^{6}$ and is so far the only trial directly comparing two fixed combinations in all patients. This study found that ACE inhibitor+CCB had significant superiority over benazepril+thiazide diuretic, even in the elderly. ${ }^{6}$ In addition, the COLM study ${ }^{7}$ was a Prospective Randomized Open Blinded End point (PROBE) study with a response-dependent dose titration scheme in elderly Japanese high-risk hypertensive patients. In the COLM study, ARB was combined with $\mathrm{CCB}$ or thiazide diuretic and the safety and tolerability profiles observed suggested that $\mathrm{ARB}+\mathrm{CCB}$ may be preferable to $\mathrm{ARB}+$ thiazide diuretic even at a very low dose. ${ }^{5}$ However, the COLM study was not able to detect statistically significant differences in the primary composite end points of cardiovascular morbidity and mortality, including renal events, between the two treatment arms due to the low incidence of cardiovascular events, as often occurs in clinical trials in Japan. ${ }^{8,9}$ The opposite conclusions with regard to the association of blood pressure control with clinical outcomes between the two trials may be explained by the differences in genetic background and/or lifestyle between Western countries and East Asian countries, especially Japan, where the incidence of cardiovascular events is lower and the incidence of stroke is higher than the incidence of coronary artery disease due to the high salt intake. ${ }^{10,11}$ Furthermore, the difference in the study designs between the two studies, that is, the use of a double-blind fixed-dose combination study in the ACCOMPLISH trial ${ }^{6} v$ s. the use of a PROBE study involving two-drug combinations in the COLM study, ${ }^{7}$ may also have caused the differences in the reduction of cardiovascular events and in the safety profile.

Similarly, the OlmeSartan and Calcium Antagonists Randomized (OSCAR) study showed that $\mathrm{ARB}+\mathrm{CCB}$ combination conferred greater benefit in preventing cardiovascular events in elderly patients than high-dose $\mathrm{ARB}$ alone. ${ }^{8}$ In contrast, in a sub-analysis of the Combination Therapy of Hypertension to Prevent Cardiovascular Events (COPE) trial comparing three combinations, that is, the combination of $\mathrm{CCB}$ with an $\mathrm{ARB}$, a $\beta$-blocker or a thiazide diuretic, ${ }^{12}$ little difference was observed in the primary cardiovascular events among the three treatment groups in elderly hypertensive patients. However, hyperuricemia and hypokalemia were more frequently reported in the benidipine-thiazide diuretic group and hyperkalemia was more frequently only in the benidipine-ARB group.

The adverse reactions associated with the combination treatments are mainly predicted from the known side effects of the individual drugs, and the decreased prevalence of symptoms and adverse metabolic effects with twodrug treatments in low-dose combinations and an increase in efficacy and a reduction in adverse drug reactions are also expected, as previously reported. ${ }^{1}$ Several clinical trials performed in Japan, including the COLM study, ${ }^{5,7}$ indicate that CCB-based combination regimens are preferable, especially for elderly hypertensive patient safety. ${ }^{8,12}$ Taken together, these findings suggest that, mainly 


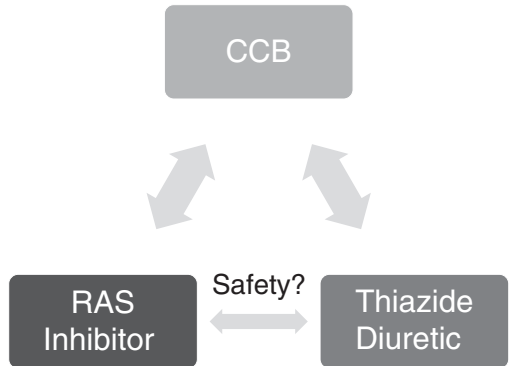

Figure 1 Combination of two drugs in the elderly. Angiotensin-converting enzyme (ACE) inhibitor or angiotensin receptor blocker (ARB)+CCB, ACE inhibitor or ARB+thiazide diuretic and $C C B$ thiazide diuretic are similarly effective in inhibiting the cardiovascular events and recommended as a combination therapy for the treatment of hypertension. ${ }^{1}$ However, in this issue, the sub-analysis of the Combinations of Olmesartan study raised the concern about the safety and tolerability issue in the ARB and thiazide diuretic combination. ${ }^{5}$ RAS, renin-angiotensin system; CCB, calcium channel blocker. A full color version of this figure is available at Hypertension Research online.

from the viewpoint of the safety profile, $\mathrm{CCB}$ combined with thiazide diuretic or an $\mathrm{ARB}$ should be recommended as a combination treatment rather than the ARB-thiazide diuretic combination for elderly Japanese hypertensive patients (Figure 1).

Compliance with combination therapy is also important for achieving the target blood pressure and it may impact clinical outcomes. ${ }^{13,14}$ A large proportion of elderly patients will discontinue or take the drugs inappropriately; a drug's side-effect profile has been demonstrated to contribute to poor compliance. ${ }^{1}$ The results of the safety profile in the COLM study, ${ }^{5,7}$ are supported by the previous report, ${ }^{1,4}$ suggesting that the survival rates of patients prescribed CCBs and ARBs were similar and were the highest compared with other classes of drugs, probably due to the occurrence of fewer side effects. The prescription rates for other drug classes, except for thiazide diuretics, showed constant declines during the study period. ${ }^{4}$ In contrast, the cumulative rates of discontinuation of the study drugs were similar in the ACCOMPLISH trial. ${ }^{6}$ The most common reasons for discontinuation of the ACCOMPLISH trial medication were adverse events and laboratory test abnormalities, and the number of patients who permanently withdrew from the study was also similar in the two groups. The differences in compliance between the two studies may result from the study drugs or study designs, that is, the use of a doubleblind study involving fixed-dose combination, ACE inhibitor with CCB or thiazide diuretic, in the ACCOMPLISH trial ${ }^{6}$ vs. the use of a PROBE study involving two-drug combinations, $\mathrm{ARB}$ with $\mathrm{CCB}$ or thiazide diuretic, in the COLM study. ${ }^{7}$ It is also possible that the investigators' knowledge and the information bias related to a study drug influenced their safety reporting, even in a randomized and double-blinded design. ${ }^{15}$

Little evidence has been accumulated to determine which of two options, increasing the dosage of a single drug or introducing combination therapy with other drugs, should be selected as a therapeutic strategy for the treatment of hypertension in Japan. However, one of these options can be selected by considering the safety profile and likelihood of compliance and their compelling indications in addition to the clinical outcome for each antihypertensive drug under the physician's consideration.

\section{CONFLICT OF INTEREST}

SU received consultant fee from Boehringer Ingelheim Japan, honoraria from Kyowa Hakko Kirin, Takeda Pharmaceutical, Mochida Pharmaceutical, Eisai and Asuka Pharmaceutical and grant from Maruha Nichiro Holdings.

\section{ACKNOWLEDGEMENTS}

A part of this work was supported by JSPS KAKENHI Grant Number 24591115 to SU.

1 Shimamoto K, Ando K, Fujita T, Hasebe N, Higaki J, Horiuchi M, Imai $\mathrm{Y}$, Imaizumi $\mathrm{T}$, Ishimitsu $\mathrm{T}$, Ito $\mathrm{M}$, Ito $\mathrm{S}$, Itoh $\mathrm{H}$, Iwao $\mathrm{H}$, Kai $\mathrm{H}$, Kario $\mathrm{K}$, Kashihara $\mathrm{N}$, Kawano Y, Kim-Mitsuyama S, Kimura G, Kohara K, Komuro I, Kumagai H, Matsuura H, Miura K, Morishita R, Naruse M, Node K, Ohya Y, Rakugi H, Saito I, Saitoh S, Shimada K, Shimosawa T, Suzuki H, Tamura K, Tanahashi N, Tsuchihashi T, Uchiyama M, Ueda S, Umemura S. Japanese Society of Hypertension Committee for Guidelines for the Management of Hypertension. The Japanese Society of Hypertension Guidelines for the Management of Hypertension (JSH 2014). Hypertens Res 2014; 37: 253-387.
2 Law MR, Wald NJ, Morris JK, Jordan RE. Value of low dose combination treatment with blood pressure lowering drugs: analysis of 354 randomised trials. BMJ 2003; 326: 1427.

3 Wald DS, Law M, Morris JK, Bestwick JP, Wald NJ. Combination therapy versus monotherapy in reducing blood pressure: meta-analysis on 11000 participants from 42 trials. Am J Med 2009; 122: 290-300.

4 Kohro T, Yamazaki T, Sato H, Ohe K, Nagai R. The impact of a change in hypertension management guidelines on diuretic use in Japan: trends in antihypertensive drug prescriptions from 2005 to 2011. Hypertens Res 2013; 36: 559-563.

5 Saruta T, Ogihara T, Saito I, Rakugi H, Shimamoto K, Matsuoka H, Teramukai S, Higaki J, Ito S, Shimada K for the COLM Investigators. Comparison of olmesartan combined with a calcium channel blocker or a diuretic in elderly hypertensive patients (COLM study): safety and tolerability. Hypertens Res 2015; 38: 132-136.

6 Jamerson K, Weber MA, Bakris GL, Dahlof B, Pitt B, Shi V, Hester A, Gupte J, Gatlin M, Velazquez EJ. ACCOMPLISH Trial Investigators. Benazepril plus amlodipine or hydrochlorothiazide for hypertension in highrisk patients. N Engl J Med 2008; 359: 2417-2428.

7 Ogihara T, Saruta T, Rakugi H, Saito I, Shimamoto K, Matsuoka H, Shimada K, Ito S, Horiuchi M, Imaizumi T, Takishita S, Higaki J, Katayama S, Kimura G, Umemura S, Ura N, Hayashi K, Odawara M, Tanahashi $\mathrm{N}$, Ishimitsu T, Kashihara N, Morita S, Teramukai S. COLM Investigators. Combinations of olmesartan and a calcium channel blocker or a diuretic in elderly hypertensive patients: a randomized, controlled trial1. J Hypertens 2014; 32: 2054-2063.

8 Ogawa H, Kim-Mitsuyama S, Matsui K, Jinnouchi T, Jinnouchi $H$, Arakawa KOlmeSartan and Calcium Antagonists Randomized (OSCAR) Study Group. Angiotensin II receptor blocker-based therapy in Japanese elderly, high-risk, hypertensive patients. Am J Med 2012; 125: 981-990.

9 Matsuzaki M, Ogihara T, Umemoto S, Rakugi H, Matsuoka H, Shimada K, Abe K, Suzuki N, Eto T, Higaki J, Ito S, Kamiya A, Kikuchi K, Suzuki H, Tei C, Ohashi Y, Saruta T. Combination Therapy of Hypertension to Prevent Cardiovascular Events Trial Group. Prevention of cardiovascular events with calcium channel blocker-based combination therapies in patients with hypertension: a randomized controlled trial. J Hypertens 2011; 29: 1649-1659.

10 Hata J, Kiyohara Y. Epidemiology of stroke and coronary artery disease in Asia. Circ J 2013; 77: 1923-1932.

11 Katsuya T, Ishikawa K, Sugimoto K, Rakugi H, Ogihara T. Salt sensitivity of Japanese from the viewpoint of gene polymorphism. Hypertens Res 2003; 26: 521-525.

12 Ogihara T, Matsuzaki M, Umemoto S, Rakugi H, Matsuoka H, Shimada K, Higaki J, Ito S, Kamiya A, Suzuki H, Ohashi Y, Shimamoto K, Saruta T. Combination Therapy of Hypertension to Prevent Cardiovascular Events Trial Group. Combination therapy for hypertension in the elderly: a sub-analysis of the Combination Therapy of Hypertension to Prevent Cardiovascular Events (COPE) Trial. Hypertens Res 2012; 35: 441-448.

13 Granger BB, Swedberg K, Ekman I, Granger CB, Olofsson B, McMurray JJ, Yusuf S, Michelson EL, Pfeffer MA. CHARM investigators. Adherence to candesartan and placebo and outcomes in chronic heart failure in the CHARM programme: double-blind, randomised, controlled clinical trial. Lancet 2005; 366 : 2005-2011.

14 Shin S, Song H, Oh SK, Choi KE, Kim H, Jang S. Effect of antihypertensive medication adherence on hospitalization for cardiovascular disease and mortality in hypertensive patients. Hypertens Res 2013; 36: 1000-1005.

15 Takabayashi N, Urushihara H, Kawakami K. Biased safety reporting in blinded randomized clinical trials: meta-analysis of angiotensin receptor blocker trials. PLoS One 2013; 8: e75027. 